\title{
PEMBERDAYAAN MASYARAKAT BERBASIS KETAHANAN PANGAN MELALUI PENGOLAHAN ABON DARI IKAN NILA DI DESA PRINGGARATA KECAMATAN PRINGGARATA KABUPATEN LOMBOK TENGAH
}

\author{
Abdul Azis ${ }^{1}$, Erna Safitri ${ }^{2}$, Irnawati ${ }^{3}$, Suparmin $^{4 *}$ \\ ${ }^{1}$ Fakultas Peternakan, Universitas Mataram \\ 2 Fakultas Teknologi Pangan dan Agroindustri, Universitas Mataram \\ ${ }^{3}$ Fakultas Keguruan dan IImu Pendidikan, Universitas Mataram \\ ${ }^{4}$ Fakultas Pertanian, Universitas Mataram \\ *Co-Author e-mail: suparminjinem@gmail.com
}

\begin{abstract}
ABSTRAK. Desa Pringgarata, Kecamatan Pringgarata, merupakan salah satu desa penghasil perikanan dan pertanian di Kabupaten Lombok Tengah. Kendala yang dihadapi oleh masyarakat adalah kurangnya tingkat kesadaran tentang pengolahan hasil perikanan untuk menambah nilai jual ikan. Alternatif solusi yang dapat dilakukan untuk mengatasi kendala tersebut adalah dengan mengadakan sosialisasi serta pelatihan pengolahan ikan nila menjadi abon untuk meningkatkan ketahanan pangan masyarakat Desa Pringgarata. Tujuan dari program pengabdian ini adalah memberdayakan masyarakat Desa Pringgarata dalam membuat abon yang berbahan dasar ikan nila. Metode yang digunakan adalah metode partisipasi dan sosialisasi. Hasil dari program pemberdayaan masyarakat ini adalah masyarakat Desa Pringgarata berpotensi untuk membuat dan mengembangkan produk abon dari ikan nila. Hasil monitoring dan evaluasi menunjukkan bahwa partisipasi dan sosialisasi masyarakat cukup banyak dapat dilihat dari antusias masyarakat yang tinggi dalam pengolahan ikan nila menjadi abon. Dengan demikian dapat meningkatkan ketahanan, sehingga masyarakat Desa Pringgarata dapat berkomitmen dalam mengembangkan abon dari ikan nila sebagai upaya berkelanjutan dari program pengembangan perikanan.
\end{abstract}

Kata kunci : Pringgarata, Ikan Nila, Abon

ABSTRACT. Pringgarata Village, Pringgarata District, is one of the fisheries and agricultural producing villages in Central Lombok Regency. The obstacle faced by the community is the lack of awareness about the processing of fishery products to add value to the sale of fish. The alternative solution that can be done to overcome these obstacles is by conducting socialization and training on processing tilapia into shredded meat to improve the food security of the Pringgarata Village community. The purpose of this service program is to empower the people of Pringgarata Village to make abon made from tilapia. The method used is the method of participation and socialization. The result of this community empowerment program is that the people of Pringgarata Village have the potential to make and develop abon products from tilapia. The results of monitoring and evaluation indicate that community participation and socialization can be seen quite a lot from the high enthusiasm of the community in processing tilapia into shredded meat. Thus it can increase resilience, so that the people of Pringgarata Village can commit to developing shredded fish from tilapia as a sustainable effort from the fisheries development program.

Kayword : Pringgarata, Tilapia, Abon. 


\section{PENDAHULUAN}

Ikan adalah salah satu sumber penghasilan hidup masyarakat di Indonesia. Dengan potensi sumber daya yang tinggi, maka sumber daya alam ini mampu menjadi penggerak pertumbuhan ekonomi nasional. Sayangnya, ikan tidak dapat segar dengan lama dan akhirnya mempengaruhi kualitas ikan-ikan tersebut.

Namun dewasa ini banyak hasil olahan ikan yang dilakukan guna memperoleh daya simpan ikan yang lama dengan kualitas yang baik. Pengolahan hasil perikanan ini dilakukan dengan cara fisika maupun secara kimiawi. Di pasar sendiri banyak dijumpai hasil olahan ikan yang enak tetapi tidak tahan lama. Salah satu inovasi yang dapat dikembangkan dari ikan untuk meningkatkan umur simpan dan nilai tambah ikan adalah mengolahnya menjadi abon. Abon ikan adalah daging ikan yang dicincang dan dikeringkan dengan penambahan bumbu-bumbu tertentu. Jenis olahan abon ikan merupakan salah satu usaha diversifikasi pengolahan hasil perikanan. Dibandingkan dengan bentuk pengolahan tradisional lainnya, abon ikan mempunyai daya awet yang relatif lama, yaitu masih bisa diterima pada penyimpanan selama 50 hari pada suhu kamar.

Salah satu potensi Desa Pringgarata adalah perikanan. Adapun jenis ikan yang dikelolah oleh beberapa masyarakat Desa Pringgarata adalah ikan nila. Biasanya, ikan dijual langsung ke pengepul hingga sampai ke tangan konsumen dalam keadaan kurang segar. Oleh karena itu, kami melakukan percobaan pengolahan abon berbahan dasar ikan nila untuk meningkatkan umur simpan ikan nila. Berdasarkan latar belakang di atas dilakukan penelitian "Pengolahan Abon dari Ikan Nila untuk Meningkatkan Ketahanan Pangan Masyarakat Desa Pringgarata Kecamatan Pringgarata Kabupaten Lombok Tengah". Penelitian ini bertujuan untuk membuat abon dari ikan nila agar menambah umur simpan dan nilai jual ikan.

Hasil yang diharapkan dari penelitian ini adalah dapat meningkatkan umur simpan ikan sehingga memberikan nilai jual pada ikan nila yang telah dijadikan abon, menambah nilai guna ikan, meningkatkan ketahanan pangan, serta dapat mengembangkan keterampilan dan kreatifitas masyarakat Desa Pringgarata.

\section{METODE PELAKSANAAN}

Metode plaksanaan kegiatan program pemberdayaan yang digunakan adalah metode partisipasi dan sosialisasi.

\section{Waktu dan Tempat}

Kegiatan dilakukan selama 2 minggu di mulai sejak tanggal 02 Februari sampai dengan 16 Februari 2019 di Desa Pringgarata, Kecamatan Pringgarata, Kabupaten Lombok Tengah.

\section{Alat dan Bahan}

Alat yang digunakan dalan Program ini adalah wajan, kompor, panci, pengaduk, blender, alat pres. Sedangkan bahan yang digunakan adalah ikan nila, merica, ketumbar, cabai, serei, garam, gula pasir, kunyit, jahe, laos, bawang merah, bawang putih, daun salam dan santan kelapa.

\section{Prosedur Kerja Pembuatan Abon Ikan Nila}

Prosedur kerja pembuatan pupuk organik cair adalah :1) Mempersiapkan alat dan bahan, 2) Rendam ikan nila dengan jeruk nipis dan garam selama 15-30 menit, 3)Kukus ikan nila 
dengan daun salam selama 30 menit, 4) Suwir ikan nila yang telah di kukus untuk memisahkan tulang dengan daging, 5) Panaskan wajan tumis bumbu halus, tambahkan serai, daun salam, tumis sampai berubah warna, 6) Kemudian masukkan santan, tunggu sampai mendidih, masukkan ikan, aduk perlahan (biar santan tidak pecah). Aduk sampai santan kering dan berubah warna.

\section{Bentuk Kegiatan}

Bentuk kegiatan secara keseluruhan ini adalah 1) Persiapan program, 2) Sosialisasi tentang abon, 3) Pelatihan Pembuatan abon dari ikan nila, 4) Monitoring dan evaluasi.

\section{Metode Pengumpulan dan Analisis Data}

Metode pengumpulan data pada program ini adalah dengan membandingkan jumlah ikan nila yang digunakan dengan jumlah abon yang dihasilkan. Analisis data menggunakan deskriptif kualitatif.

\section{HASIL DAN PEMBAHASAN}

Program pemberdayaan masyarakat desa pringgarata dilakukan secara tersetruktur dan melibatkan masyarakat secara langsung.

\section{Pelaksanaan Program Pmeberdayaan Masyarakat}

Kegiatan pemberdayaan masyarakat ini dimulai dengan persiapan progran yang meliputi survei lokasi. Hasil survei menujukan bahwa kendala yang dihadapi masyarakat Pringgarata antara lain 1) Banyak masyarakat desa yang membudidayakan ikan nila menggunakan keramba, 2) Ikan dijual secara langsung tanpa diolah terlebih dahulu, 3) Ikan sampai ke tangan konsumen dalam keadaan kurang segar, 4) Kurangnya kreatifitas masyarakat dalam mengolah ikan nila untuk meningkatkan umur simpan dan nilai jualnya.

Tahap selaanjutnya adalah persiapan instrumen monitoring dan evaluasi yaitu pengetahuan masyarakat, selanjutnya perijinan dan pembahasan program bersama masyarakat Pringgarata, Kecamatan Pringgarata, Lombok Tengah.

\section{Penyuluhan dan Pelatihan Pembuatan Abon Ikan Nila}

Penyuluhan dan pelatihan pembuatan abon ikan nila di desa Pringgarata dilakukan di posko KKN. Penyuluhan pertama tentang pemanfaatan ikan nila menjadi abon. Penyuluhan ini diadakan untuk menumbuhkan dan meningkatkan kesadaran ibu-ibu rumah tangga mengenai inovasi produk yang berbahan dasar ikan nila. Selain itu, program ini juga bertujuan untuk meningkatkan keterampilan ibu-ibu dalam mengolah ikan agar dapat bertahan lama, memiliki nilai jual yang tingga sehingga dapat dijadikan sebagai salah satu alternatif usaha. 


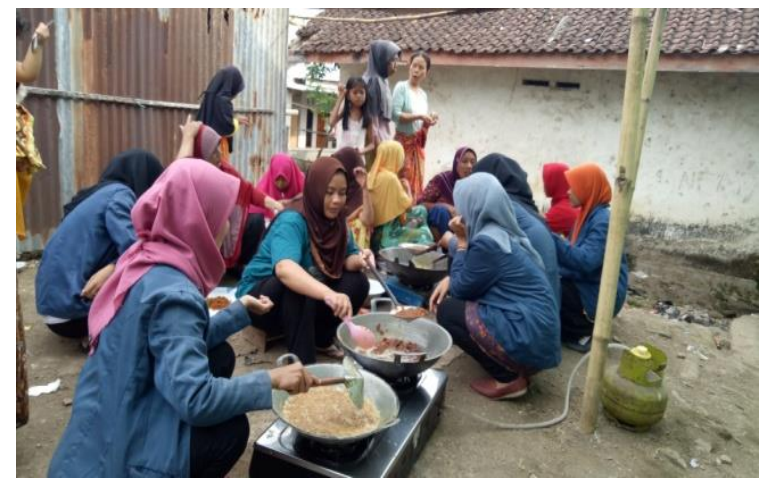

Gambar 1. Pelatihan Pengolahan Ikan Nila Menjadi Abon Ikan Nila

Pelatihan kedua yaitu mengenai pembuatan abon ikan nila yang dilakukan di rumah ketua ibuibu PKK yang dihadiri oleh ibu-ibu PKK dan warga sekitar dusun. Kegiatan ini dilaksankan dengan memanfaatkan ikan nila sebagai bahan pengolahan abon sehingga dapat berguna bagi masyarakat khususnya pemilik usaha keramba ikan di desa Pringgarata selatan. Pelatihan ini bertujuan untuk membuat sekaligus mengetahui proses pembuatan abon yang berbahan dasar ikan nila yang akan menambah umur simpan dan nilai jual ikan sehingga diharapkan dapat meningkatkan ketahanan pangan di desa Pringgarata.

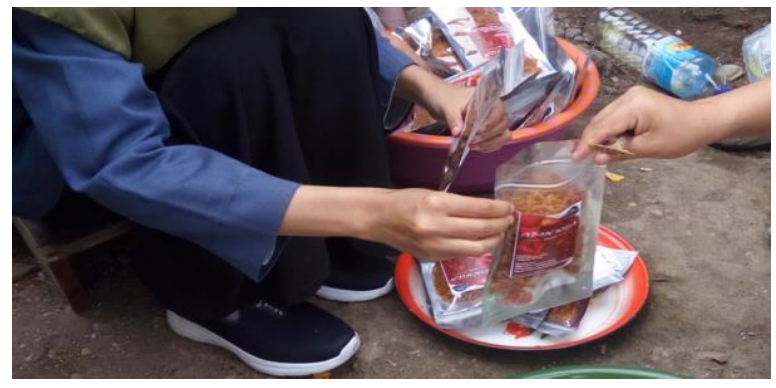

Gambar 2. Proses Pengemasan Abon Ikan Nila

\section{Monitoring dan Evaluasi}

Monitoring dan evaluasi kontinu dilakukan bersamaan dengan pedampingan program. Hasil monitoring berkelanjutan Evaluasi program secara umum menunjukan bahwa masyarakat dan kelompok ibu-ibu PKK desa Pringgarata berkomitmen untuk memanfatkan dan mengolah ikan nila sebagai abon ikan guna meningkatan umur simpan ikan dan menambah kegiatan serta keterampilan masyarakat desa.

\section{KESIMPULAN}

Simpulan dari program penyuluhan dan pelatihan pembuatan abon ikan nila kepada masyarakat adalah : (1) Masyarakat desa Pringgarata dapat mengolah ikan nila untuk dijadikan abon ikan nila; (2) untuk meningkatkan nilai tambah ikan nila; (3) menambah keterampilan dan pengetahuan masyarakat Desa Pringgarata; \& (4) Berkomitmen dalam mengembangkan berkelanjutan program. 


\section{REFERENSI}

Balitbangkes Kesehatan Kemenkes RI. 2010. Riset Kesehatan Dasar. Jakarta: Balitbangkes Kesehatan Kemenkes RI.

Karyono dan Wachid. 1982. Petunjuk Praktek Penanganan dan Pengolahan Ikan. Jakarta : Departemen Pendidikan dan Kebudayaan.

Kementerian Kelautan dan Perikanan. 2014. Statistik Perikanan Tangkap Indonesia Tahun 2014. Jakarta : Direktorat Jendral Perikanan Tangkap.

Purwaningsih, S. 1999. Studi Pembuatan Abon Ikan Cakalang (Katsuwonis pelamis). Diakses dari http://repository.ipb.ac.id. Pada Hari, Sabtu 01 Februari 2019 Pukul 09:00 WITA.

Setyaningsih, Dwi. 2010. Analisis Sensori untuk Industri Pangan dan Agro. Bogor: IPB Pres.

Suryani, A, Erliza Hambali, Encep Hidayat. 2007. Membuat Aneka Abon. Jakarta Penerbit Swadaya.

Tanjung, A. 2010. Rancangan Percobaan. Bandung : Tantaramesta Asosiasi Direktori Indonesia.

Ulfa. 2012. Abon ikan cakalang (katsuwonus pelamis). Universitas Sultan Ageng Tirtayasa : Jurusan perikanan Fakultas Pertanian Universitas Sultan Ageng Tirtayasa.

Utami, 2010. Pengaruh Variasi kadar gula dan lama Pengukusan Terhadap Kualitas Abon. Yogyakarta : Universitas Atma Jaya Yogyakarta.

Winarno, F.G. 2008. Kimia Pangan dan Gizi: Edisi Terbaru. Jakarta: Gramedia Pustaka Utama. 